\title{
Mechanical properties of fly ash geopolymer mortar reinforced with carbon fibers
}

\author{
Qais Frayyeh $^{1 *}$, and Ahmed Swaif ${ }^{1}$ \\ ${ }^{1}$ Building and Construction Engineering. Department, University of Technology, Baghdad, Iraq.
}

\begin{abstract}
Portland cement industry releases high amounts of $\mathrm{CO} 2$, so efforts have been made for alternative binders. Geopolymers are one of the highlighted elective binders. The aims of this study are to produce fly ash Geopolymer boards reinforced with carbon fibers and investigate the mechanical properties of several blends of fly ash Geopolymer mortar reinforced with carbon fibers (FGC). Carbon fibers (CF) were added at different percentages (WF) of $0.2 \%, 0.5 \%, 1 \%$, and $1.5 \%$ by weight. The sodium hydroxide condensation of 8 molars, sodium silicate to sodium hydroxide weight ratio of 2.0 , the alkaline liquid/binder proportion of 0.47 and the dry heat curing of $70^{\circ} \mathrm{C}$ for 24 hours were utilized as a piece of blends. Fresh and hardening state properties such as Flow capacity, flexural strength and compressive strength, and physical properties such as bulk density were determined from the 3-day FGC samples after the curing process. The results obtained from this study, show that the uses of CF were significant in improving the compressive and flexural strength due to the bonding characteristics of fibers with Geopolymer pastes. Then again, the used of CF results in slightly decrease of the bulk density. The optimal compressive and flexural strength outcomes were at weight percentage $1 \%$ of CF.
\end{abstract}

\section{INTRODUCTION}

Another type of substances with bond attributes designated geopolymer has been created as of late [1]. Alkaline activation, normally alluded to as geopolymerization, is characterized as a process which changes the shiny constituents in all around compacted and concrete highlighted composites. An intensive base is substantial to expand the surface hydrolysis of the particles of crude substances with a disintegration comprising of a specific sum of silica and alumina found in substances amid polymerization. This medium can be gotten by single or joined base arrangements alluded to as activators [2].

Alkali activator solutions assume a critical part in the disintegration of $\mathrm{Si}$ and $\mathrm{Al}$ oxides. Henceforth, geopolymers are combined by blending the most wellknown alkaline activators that are strong alkaline solutions, for example, sodium hydroxide $(\mathrm{NaOH})$, potassium hydroxide $(\mathrm{KOH})$, potassium silicate or sodium silicate with aluminosilicate receptive materials [3] [4].

The concentration of the activator significantly affects the compressive qualities of the geopolymers. The perfect condensation of the activator expands the quality of the geopolymer. Separated from the perfect condensation, a few misfortunes may happen in the mechanical characteristics of the substance because of the free $\mathrm{OH}$ particles in the alkali-activated framework

*Corresponding author: jwd ks@yahoo.com which can alter the geopolymer structure of the substance. Curing and age temperature of the geopolymers are different factors which affect the compressive quality of the samples. Be that as it may, for these factors to be compelling, adequate concentration of activator must be accessible in the medium amid geopolymerization in light of the fact that $\mathrm{NaOH}$ concentration affects the quality esteems than on the curing temperature and curing time esteems [2] [5][6]. Geopolymers are by and large formed by fly ash initiated at low temperatures. Fly fiery remains a mechanical waste with pozzolanic characteristics acquired from warm power plants and utilized rather than cement in concrete development. $\mathrm{SiO} 2$ and $\mathrm{Al} 2 \mathrm{O} 3$ in the fly ash react with calcium hydroxide shaped because of hydration of Portland type and begin a pozzolanic response. Hence, fly fiery remains can be utilized rather than Portland type [1].

Fly ash has large amounts of shapeless silica and alumina furthermore, is frequently blended with base solution for break down them. Silicates start to break up when the fly fiery remains come into contact with alkali Solution. Fly fiery remains can be utilized as a source substance in the era of geopolymers since geopolymerization is basically in view of the aluminasilicate chain. In any case, the sort and condensation of the base solution assume an essential part in the arrangement of the fly fiery remains. The dissolvability 
of Al3+ and Si4+ ions in sodium hydroxide solvency is higher than in potassium hydroxide arrangement [7] [8]. Along these lines, $\mathrm{NaOH}$ importantly affects the framework and the compressive quality of the geopolymers [9]. Si, $\mathrm{Al}$ and other minor ions start to break down when the fly fiery remains contact with $\mathrm{NaOH}$. The measure of disintegration relies on upon the $\mathrm{NaOH}$ condensation and disintegration time [1]. The $\mathrm{NaOH}$ fixation impacts the deterioration method and the official of strong particles in the geopolymeric framework's last structure of the watery stage [9]. The blend of fly powder with 10 molarity (M) of $\mathrm{NaOH}$ is appropriate for the geopolymer blend [1].

The readied blend can be exposure to curing like room temperature or like a given temperature. Aluminosilicate responsive substances break up in strong alkaline arrangements and free $\mathrm{SiO} 4$ and $\mathrm{AlO} 4$ tetrahedral structure forms. In any case, the reaction of the fly ash debris in the creation of geopolymers is low at ambient temperatures [3]. A long these lines, the geopolymerization procedure through which the material can accomplish high compressive strength at given temperatures in the vicinity of 40 and $95{ }^{\circ} \mathrm{C}$ can create [6] [9] [10] [11]. The microstructure of the fly ash geopolymers contains aluminosilicate gel, unreacted fly ash and other precious stone phases [12].

Past reviews have presumed that Class F fly ash is a decent hotspot for geopolymers [13] and that $\mathrm{NaOH}$ is superior to other activators for the initiation of the fly ash in the creation of geopolymers.

At the point when $\mathrm{NaOH}$ is utilized together with water glass, the compressive strength of the geopolymer material is higher than when just $\mathrm{NaOH}$ is utilized. The explanation for this is the way that in the geopolymerization handle, water glass expands the response items in which the Si substance is higher, and gives more mechanical quality [14]. Different reviews demonstrate that when utilizing the water glass with base activators, compressive and flexural quality increment [15]; however, when water glass is utilized together with $\mathrm{NaOH}$, rather than utilizing just $\mathrm{NaOH}$, tests increment huge quality even in one day [16] [17]. In any case, water glass in powder shape displays brings down execution than water glass in fluid frame [15].

A few reviews in the literature have tried blends of various curing times and temperatures with $\mathrm{NaOH}$ fixations.

Among these reviews, analysts discovered both geopolymers in which fly ash and bottom ash were utilized [18], and additionally geopolymers which were orchestrated with fly ash, kaolin, sodium silicate solution and $\mathrm{NaOH}$ [11]. Furthermore, different reviews in the literature are delivered light inorganic polymers by incorporating Class F fly ash, metakaolin and lightweight aggregates with $\mathrm{NaOH}$ sodium silicate solution [19] or created polymers by utilizing fly ash and sodium silicate solution [20], readiness and portrayal of new geopolymer-epoxy sap mixture mortars [21] and some other studies combined 7-day fly powder based geopolymers [22] and created 7-day fly ash-based geopolymers mortars [23]. The past concentrates for the most part centered on geopolymer paste. In these reviews, geopolymer materials were subjected to long curing times, and drawn out stretches of time were considered for the discovery of their properties. In any case, in the present review, $\mathrm{NaOH}$ and sodium silicate solution (water glass) were utilized to initiate the Class F fly ash to decide the physical and mechanical properties of the orchestrated geopolymer materials in a brief timeframe.

The adjustments in the geopolymerization procedure and the properties of the last item were explored by curing geopolymer mortars, which were readied utilizing alkaliactivated fly ash and crushed sand, with varying $\mathrm{NaOH}$ concentrations, temperatures, also, periods of time. Along these lines, the adjustments in the properties of the geopolymer mortars in brief timeframes were uncovered by distinguishing the connections between the alkali solution concentrations, curing temperature and curing time.

\section{Research significance}

The target of this examination is to survey the impacts of utilizing $\mathrm{CF}$ at various weight portions in a blend of (FGM) and concentrate some mechanical characteristics of this mortar.

\section{Materials}

The raw materials used to synthesize fly ash geopolymers include Turkish hard coal fly ash from power station Iskenderun (ASTM class F fly ash), the composition of the fly ash utilized is shown in Table 1 and Figure 1shows the detailed particle size distributions determined by the standard test method ASTM D422 [24],the alkaline activator was a mixture of chemical grade $\mathrm{NaOH}$ solution 8 molarity (99\% purity quotient, local market)and liquid sodium silicate solution with the chemical composition of $\mathrm{SiO} 2=28.75 \%, \mathrm{Na} 2 \mathrm{O}=13.75 \%$ and $\mathrm{H} 2 \mathrm{O}=57.5 \%$ (local market), natural sand was used, A high range water reducer superplasticizer based on modified sulfonated naphthalene formaldehyde condensate was used to enhance workability of fly ash Geopolymer mortar and fibers used in this study were Carbon fibers with $12 \mathrm{~mm}$ in length, their properties shown in Table 2.

Table 1. Fly Ash Chemical Composition

\begin{tabular}{|c|c|}
\hline Component & Mass \% \\
\hline $\mathrm{Fe}_{2} \mathrm{O}_{3}$ & 5.98 \\
\hline $\mathrm{SiO}_{2}$ & 65.65 \\
\hline $\mathrm{Al}_{2} \mathrm{O}_{3}$ & 17.69 \\
\hline $\mathrm{CaO}$ & 0.98 \\
\hline $\mathrm{SO}_{3}$ & 0.19 \\
\hline $\mathrm{LOI}$ & 3.1 \\
\hline $\mathrm{Na}_{2} \mathrm{O}$ & 1.35 \\
\hline $\mathrm{MgO}$ & 0.72 \\
\hline $\mathrm{K}_{2} \mathrm{O}$ & 2.99 \\
\hline
\end{tabular}

Chemical composition data from the data sheet and materials safety provided by the suppliers. 


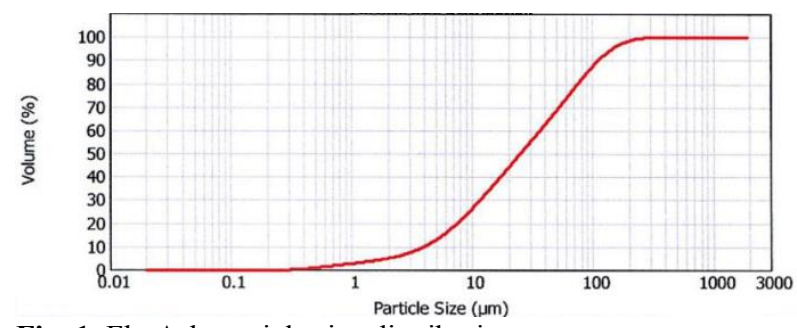

Fig. 1. Fly Ash particle size distribution

Table 2. Mechanical properties of Carbon fiber

\begin{tabular}{|c|c|}
\hline Property & Carbon fiber \\
\hline Specific gravity & 1.79 \\
\hline Tensile strength, MPa & 3900 \\
\hline Length $\mathrm{mm}$ & 12 \\
\hline Diameter $\mu \mathrm{m}$ & $10-13$ \\
\hline Elongation at break (\%) & 15 \\
\hline
\end{tabular}

Mechanical properties from the data sheet and materials safety provided by the suppliers.

\section{Mix proportion, mix detail and curing}

The mortar proportions are shown in Table 3. A total of five mortar mixtures were prepared, one of them without fibers and four mixtures with CF. The fibers were uniformly added into the mortar mixture at four different contents $(0.2 \%, 0.5 \%, 1 \%$ and $1.5 \%$ by weight of fly ash). The alkaline liquid was prepared one day before using by blending sodium silicate and sodium hydroxide arrangements, and then the base liquid was mixed with superplasticizer prior to starting of the mixing process. The dry materials (Fly Ash, Sand and Fibers) were firstly mixed for three minutes. From that point forward, the blended alkaline liquid with superplasticizer were added to dry materials and mixed for another three minutes until the mixture was homogenous. The dry heat curing system of $70^{\circ} \mathrm{C}$ for 24 hours was adopted for all specimens for this study[6] [9] [10] [11].

Table 3. The mortar mix proportions

\begin{tabular}{|c|c|}
\hline Material & Quantity $\left(\mathbf{k g} / \mathbf{m}^{\mathbf{3}}\right)$ \\
\hline Fly Ash & 900 \\
\hline Sand & 1331 \\
\hline Sodium silicate solution & 247 \\
\hline sodium hydroxide solutions(8 M) & 174 \\
\hline superplasticizer & 19 \\
\hline
\end{tabular}

\section{Mechanical and physical properties of mortar}

\subsection{Flow}

The impact of fibers on the stream of the five mortar blends is highlighted in Table 4. It is easy to note that the inclusion of $\mathrm{CF}$ in $\mathrm{FGC}$ blends reduces the flowing ability. On the other hand; a higher amount of CF makes loss flow ability [25]. In summary, the effect of CF on the flowing capacity is less than the control blend by $20 \%$ as shown in figure 2 .

\subsection{Compressive strength}

The compressive strength outcomes of mortar blends are illustrated in Table 5. The compressive strengths of geopolymer mortars containing $\mathrm{CF}$ were clearly superior to that of control mix. At 28 days, the compressive qualities of mortars containing $1 \%$ Carbon fibers increased $30.15 \%$ to $34.1 \mathrm{MPa}$ compared with $26.2 \mathrm{MPa}$ of the control mortar as illustrated in figure 3. The outcomes took after an indistinguishable inclined from those of the compressive quality, and affirmed with different examines [26] that expansion of fibers enhanced the quality of mortar and concrete. The expansion more than $1 \% \mathrm{CF}$, regardless, began to antagonistically influence the quality of geopolymer. The compressive qualities at 28 days of $1.5 \%$ of Carbon fibers reduced to $31.3 \mathrm{MPa}$. The compressive quality of the pastes were fundamentally enhanced because of the change in the mechanical security quality between the filaments and mortar, where the strands give the capacity to defer development of miniaturized scale splits and capture their engendering a while later up to a specific degree of the strands' volume portion.

\subsection{Flexural strength}

The flexural strength of the mortar mixes is shown in Table 6. The increase in the flexural strength of the blends containing a $1 \% \mathrm{CF}$ increased $44.42 \%$ to 4.76 compared with $3.29 \mathrm{MPa}$ of the control mortar, which might be on account of the better compressed and homogeneity of the fiber appropriation as appeared in figure 4. It can likewise be noticed that the expansion over $1 \% \mathrm{CF}$ somewhat diminishes the change in flexural quality, which might be on account of the physical challenges in giving a homogenous appropriation of the filaments inside the mortar blend [27].

\subsection{Bulk Density}

Table 7 shows the results of density for all mixes, and from the outcomes about, it can be seen that the expansion of $\mathrm{CF}$ in the mortar blends slightly decreases the bulk density, and this can be ascribed to the particular gravity of fiber which reduce the overall density of mortar [28] as shown in figure 5. 
Table 4. The flow of mortar blends

\begin{tabular}{|c|c|}
\hline Mix name & Flow \% \\
\hline The control & 34 \\
\hline CF $(0.2 \% \mathrm{WF})$ & 32.7 \\
\hline CF $(0.5 \% \mathrm{WF})$ & 31.3 \\
\hline CF $(1 \% \mathrm{WF})$ & 29.1 \\
\hline CF $(1.5 \% \mathrm{WF})$ & 27.2 \\
\hline
\end{tabular}

\section{Flow}

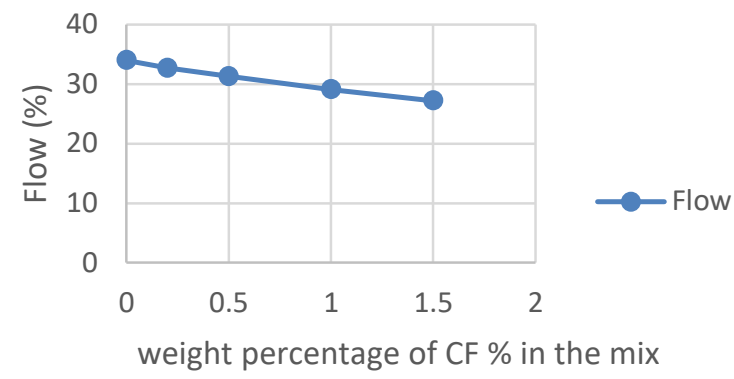

Fig. 2. Relation between flow with fiber content

Table 5. The compressive strengths of mortar blends

\begin{tabular}{|c|c|c|c|}
\hline $\begin{array}{c}\text { Mix } \\
\text { name }\end{array}$ & $\begin{array}{c}\text { Compression } \\
\text { strength } \\
\text { (age3days) } \\
\text { MPa }\end{array}$ & $\begin{array}{c}\text { Compression } \\
\text { strength } \\
\text { (age7days) } \\
\text { MPa }\end{array}$ & $\begin{array}{c}\text { Compression } \\
\text { strength } \\
\text { (age28days) } \\
\text { MPa }\end{array}$ \\
\hline The control & 16.23 & 24.33 & 26.2 \\
\hline $\begin{array}{c}\text { CF }(0.2 \% \\
\text { WF) }\end{array}$ & 17.3 & 25.8 & 28 \\
\hline $\begin{array}{c}\text { CF (0.5\% } \\
\text { WF) }\end{array}$ & 21.1 & 28 & 30.2 \\
\hline $\begin{array}{c}\text { CF (1\% } \\
\text { WF) }\end{array}$ & 24.4 & 31.9 & 34.1 \\
\hline $\begin{array}{c}\text { CF (1.5\% } \\
\text { WF) }\end{array}$ & 21.7 & 28.8 & 31.3 \\
\hline
\end{tabular}

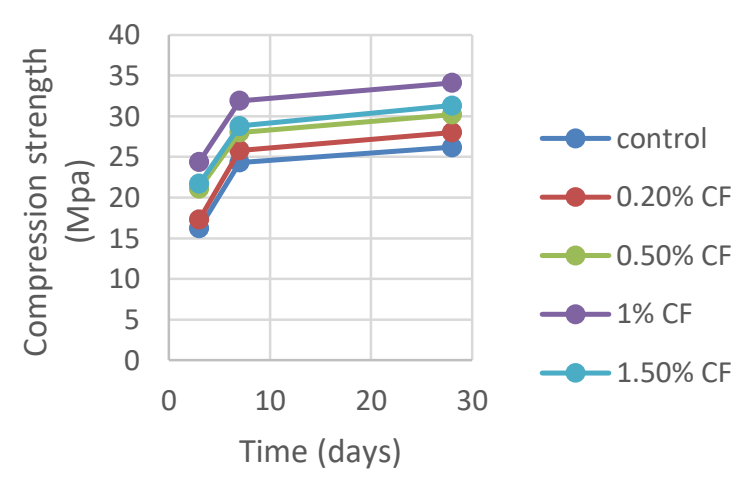

Fig. 3. Relation between compression strength with time

Table 6. The flexural strengths of mortar blends

\begin{tabular}{|c|c|c|}
\hline $\begin{array}{c}\text { Mix } \\
\text { name }\end{array}$ & $\begin{array}{c}\text { Flexural } \\
\text { strength } \\
\text { (age7days) } \\
\text { MPa }\end{array}$ & $\begin{array}{c}\text { Flexural } \\
\text { strength } \\
\text { (age28days) } \\
\text { MPa }\end{array}$ \\
\hline The control & 3.919 & 3.296 \\
\hline $\mathrm{CF}(0.2 \% \mathrm{WF})$ & 3.302 & 3.601 \\
\hline $\mathrm{CF}(0.5 \% \mathrm{WF})$ & 3.5 & 3.94 \\
\hline $\mathrm{CF}(1 \% \mathrm{WF})$ & 4.2 & 4.76 \\
\hline $\mathrm{CF}(1.5 \% \mathrm{WF})$ & 4.06 & 4.701 \\
\hline
\end{tabular}

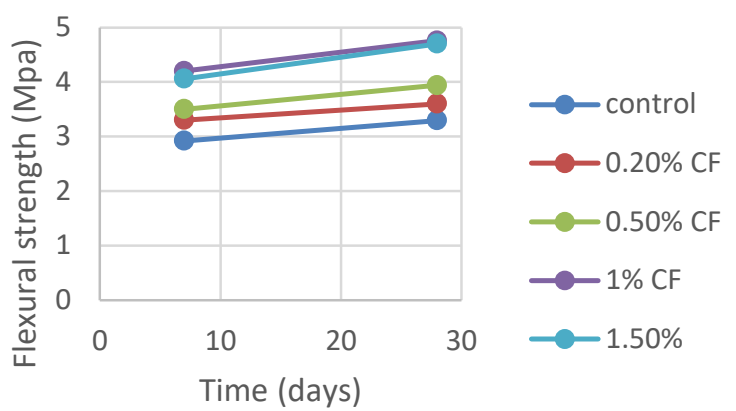

Fig. 4. Relation between flexural strength with time

Table 7. The density of mortar blends

\begin{tabular}{|c|c|}
\hline $\begin{array}{c}\text { Mix } \\
\text { name }\end{array}$ & $\begin{array}{c}\text { Density } \\
\text { (age } 28 \text { days) } \\
\mathrm{kg} / \mathrm{m}^{3} \\
\end{array}$ \\
\hline The control & 2175 \\
\hline $\mathrm{CF}(0.2 \% \mathrm{WF})$ & 2173 \\
\hline CF $(0.5 \% \mathrm{WF})$ & 2169 \\
\hline CF (1\% WF) & 2163 \\
\hline CF (1.5\% WF) & 2156 \\
\hline
\end{tabular}

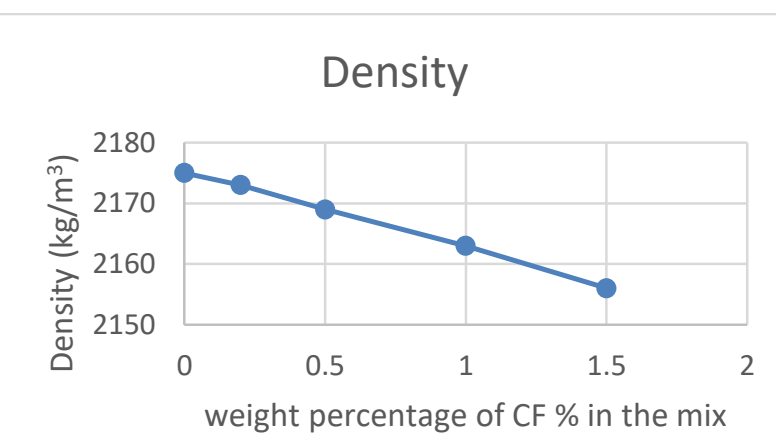

Fig. 5. Relation between bulk density with fiber content

\section{Conclusions}

In light of the aftereffects of this review, the take after conclusions could be drawn.

1. The possibility of production of fly ash geopolymer boards reinforced with $\mathrm{CR}$ with very acceptable properties which encourage to utilize the boards in several application.

2. The utilization of $\mathrm{CF}$ at little weight portions (1\% Carbon fibers) has clear effects on the properties mortar.

3. The use of CF affects the workability of fiber reinforced mortars; CF produce harsh mixes significantly with increase the weight percentage of $\mathrm{CF}$.

4. The compressive quality outcomes demonstrate that the utilization of the CF increases the compressive quality and that the best change is gotten when the $\mathrm{CF}$ are $1 \%$ of the blend. This is 
because of the mechanical bond between the paste and the $\mathrm{CF}$.

5. The flexural quality outcomes demonstrate that there is a good increment in flexural quality by expanding the fiber content. The utilization of $1 \%$ $\mathrm{CF}$ as a weight portions gives the most noteworthy increment, however past this rate there is a slight diminishing in this change.

6. The use of CF slightly reduces the density, and this may be not considered as a very significant factor if it is compatible with acceptable ranges of compressive strength.

\section{References}

[1] Rattanasak, Ubolluk, and PrinyaChindaprasirt. Minerals Engineering 22, no. 12 (2009): 1073-078.

[2] Vargas, Alexandre Silva De, Denise C.c. Dal Molin, Antônio C.f. Vilela, Felipe José Da Silva, Bruno Pavão, and Hugo Veit. Cement and Concrete Composites 33, no. 6 (2011): 653-60. doi:10.1016/j.cemconcomp.2011.03.006.

[3] Somna, Kiatsuda, Chai Jaturapitakkul, PuangratKajitvichyanukul, and PrinyaChindaprasirt. " Fuel 90, no. 6 (2011): $2118-124$. doi:10.1016/j.fuel.2011.01.018.

[4] Brough, A.r, and A. AtkinsonCement and Concrete Research 32, no. 6 (2002): 865-79. doi:10.1016/s00088846(02)00717-2.

[5] Hu, Mingyu, Xiaomin Zhu, and Fumei Long. " Cement and Concrete Composites 31, no. 10 (2009): 762-68. doi:10.1016/j.cemconcomp.2009.07.006.

[6] Bakharev, T. Cement and Concrete Research 35, no. $6 \quad$ (2005): 1224-232.

doi:10.1016/j.cemconres.2004.06.031.

[7] Jaarsveld, J. G. S. Van, and J. S. J. Van Deventer. Industrial \& Engineering Chemistry Research 38, no. 10 (1999): 3932-941. doi:10.1021/ie980804b.

[8] Deventer, J.s.j. Van. " Miner Eng 2012;29:89104." Handbook of Low Carbon Concrete, 2017, 217-62. doi:10.1016/b978-0-12-804524-4.00010-5.

[9] Panias, Dimitrios, Ioanna P. Giannopoulou, and Theodora Perraki. Colloids and Surfaces A: Physicochemical and Engineering Aspects 301, no. 1-3 (2007): 246-54. doi:10.1016/j.colsurfa.2006.12.064.

[10] Chindaprasirt, P., T. Chareerat, and V. Sirivivatnanon. Cement and Concrete Composites29, no. 3 (2007): 224-29. doi:10.1016/j.cemconcomp.2006.11.002.

[11] Swanepoel, J.c., and C.a. Strydom. Applied Geochemistry 17, no. 8 (2002): 1143-148. doi:10.1016/s0883-2927(02)00005-7.
[12] Lecomte, I., C. Henrist, M. Liégeois, F. Maseri, A. Rulmont, and R. Cloots. Journal of the European Ceramic Society 26, no. 16 (2006): 3789-797. doi:10.1016/j.jeurceramsoc.2005.12.021.

[13] Schmücker, Martin, and Kenneth J.d. Mackenzie. "Microstructure of sodium polysialatesiloxogeopolymer." Ceramics

International 31, no. 3 (2005): 433-37. doi:10.1016/j.ceramint.2004.06.006.

[14] Criado, M., A. Palomo, and A. Fernandezjimenez. $\begin{array}{llll}\text { Fuel 84, no. } 16 & \text { (2005): }\end{array}$ Doi:10.1016/j.fuel.2005.03.030.

[15] Pacheco-Torgal, Fernando, João Castro-Gomes, and Said Jalali. Construction and Building Materials 22, no. $7 \quad$ (2008): 1315-322. doi:10.1016/j.conbuildmat.2007.03.019.

[16] Fernández-Jiménez, A., and A. Palomo. Cement and Concrete Research 35, no. 10 (2005): 1984-992. doi:10.1016/j.cemconres.2005.03.003.

[17] Fernández-Jiménez, A., and A. Palomo. Fuel 82, no. 18 (2003): 2259-265. doi:10.1016/s00162361(03)00194-7.

[18] Li, Qin, Hui Xu, Feihu Li, Peiming Li, Lifeng Shen, and JianpingZhai. Fuel 97 (2012): 366-72. doi:10.1016/j.fuel.2012.02.059.

[19] Wu, Hwai-Chung, and Peijiang Sun. Construction and Building Materials 21, no. 1 (2007): 211-17. doi:10.1016/j.conbuildmat.2005.06.052.

[20] Provis, John L., Chu Zheng Yong, Peter Duxson, and JannieS.j. Van Deventer. Colloids and Surfaces A: Physicochemical and Engineering Aspects 336, no. 1-3 (2009): 57-63. doi:10.1016/j.colsurfa.2008.11.019.

[21] Colangelo, Francesco, Giuseppina Roviello, Laura Ricciotti, Claudio Ferone, and Raffaele Cioffi.

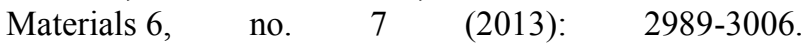
doi:10.3390/ma6072989.

[22] Jaarsveld, J.g.s. Van, J.s.j. Van Deventer, and G.c. Lukey. Materials Letters 57, no. 7 (2003): 1272-280. doi:10.1016/s0167-577x(02)00971-0.

[23] Temuujin, J., A. Van Riessen, and K.j.d. Mackenzie. Construction and Building Materials 24, no. 10 (2010): 1906-910. doi:10.1016/j.conbuildmat.2010.04.012.

[24] Standard test method for particle-size analysis of soils. West Conshohocken, PA: ASTM International, 2007. 
[25]Makhlouf, Said, SouadKhedache, DihiaDjefel, and Gilles Lefebvre. " Key Engineering Materials 550 (2013):

91-98. doi:10.4028/www.scientific.net/kem.550.91.

[26] Ramli, M., and E. Dawood. Slovak Journal of Civil Engineering XIX, no. 3 (2011). doi:10.2478/v10189011-0013-0.

[27] Dawood, EetharThanon, and MahyuddinRamli. ISRN Civil Engineering 2012 (2012): 1-5. doi:10.5402/2012/718549.
[28] Li, Bao Jia, GuoZhong Li, and Chao Ning. Advanced Materials Research 146-147 (2010): 38-41. doi:10.4028/www.scientific.net/amr.146-147.38. 